\title{
Mudanças na concepção de escrita de jovens e adultos em processo de letramento*
}

Sylvia Bueno Terzi

Júlia Sant'Ana Scavassa

Universidade Estadual de Campinas

Este trabalho tem por objetivo a análise das mudanças na concepção de escrita de jovens e adultos não escolarizados, decorrentes da participação em um curso de alfabetização de cinco meses. Os dados mostram que a maior relevância atribuída pelos sujeitos às práticas de letramento está relacionada à escrita como meio de resolução de problemas, de crescimento e satisfação pessoal e de participação social e cidadania.

This paper dicusses the changes in the conception of the written language as expressed by unschooled adolescents and adults who participated in a five-month literacy course. The data show that before the course the students considered literacy as a means for solving daily practical problems. After the course, they regarded literacy as a tool for self-improvement, social interaction and citizenship.

O objetivo deste trabalho é analisar as transformações ocorridas no conceito de língua escrita de jovens e adultos não escolarizados, potencializadas pela participação, durante o período de cinco meses, em cursos do Programa Alfabetização Solidária, oferecidos em dois pequenos municípios do sertão de Alagoas: Inhapi, com 17.498 habitantes, localizado a $263 \mathrm{Km}$ de Maceió, e Olho D'Água do Casado, com 7.057 habitantes, distante $272 \mathrm{Km}$ da capital.

Nesses cursos, os alunos foram colocados em contato com variados usos da escrita em um curto período, ao contrário do que ocorre no processo natural de letramento, em que elementos causadores de introdução de novas funções para a língua escrita numa dada comunidade surgem a intervalos relativamente grandes de tempo, dependendo das condições sócio-econômicas, culturais e políticas locais. De 1997 ao

\footnotetext{
" Trabalho parcialmente financiado pela FAPESP (Processo 01/12702-2).
} 
presente momento, período de atuação do Programa na região pesquisada, por exemplo, tivemos oportunidade de ver apenas alguns fatos que interferiram no letramento das comunidades de maneira significativa: a criação do Programa Nacional de Apoio à Agricultura Familiar, que, exigindo comprovação de propriedade das terras, colocou em foco a necessidade de registro (escritura) de transações de compra e venda de imóveis e trouxe à luz a questão de a palavra empenhada valer mais que "um papel"; a realização do primeiro concurso público para preenchimento de cargos, que provocou uma reavaliação dos critérios anteriores de seleção e introduziu novos textos: o edital, o currículo, os testes específicos, a lista de aprovados e o documento de posse; e, mais recentemente, a criação do Curso Superior de Pedagogia, oferecido pela Universidade Federal de Alagoas no sistema de ensino à distância, que trouxe os textos teóricos.

Já em cursos como os oferecidos pelo Programa nos locais estudados, que visam familiarizar os jovens e adultos com a escrita ao mesmo tempo em que são alfabetizados, o processo é de imersão. É importante, então, analisarmos os efeitos desse contato na construção e transformação do conceito de escrita desses jovens e adultos. Dois aspectos são considerados na análise: quais os usos da escrita que passam a ser relevantes para eles, e que fatores levam a essa relevância. Os resultados apontam para uma valorização progressiva da língua escrita como um meio de participação e inclusão social.

\section{Situação de letramento das comunidades envolvidas na pesquisa}

Nos municípios envolvidos na pesquisa, pouco mais da metade das populações vive na zona rural e tenta sobreviver da agricultura familiar, freqüentemente abalada pelas secas. A maior fornecedora de empregos é a prefeitura, complementada por um pequeno comércio.

A seca, a pobreza, a grande distância das cidades maiores e a péssima situação das estradas impedem o desenvolvimento geral e, principalmente, o desenvolvimento educacional. O ensino é bastante precário: na zona urbana, os professores, egressos dos fracos cursos de magistério locais, reproduzem as limitações. Na zona rural, a situação é pior, pois professores leigos, escolhidos por critérios políticos, 
trabalham, em suas próprias residências, com classes multi-seriadas, com resultados quase nulos. Daí os elevados índices de analfabetismo.

Em 1997, foi implementado nos municípios o Programa Alfabetização Solidária, programa de âmbito nacional, hoje presente em 2.004 municípios brasileiros, e internacional, atuando em Timor Leste, Moçambique, São Tomé e Príncipe e Cabo Verde, que visa a oferecer, a jovens e adultos não escolarizados, cursos básicos de domínio da língua escrita, encaminhando-os, posteriormente, a escolas de Educação de Jovens e Adultos, para a continuidade de seus estudos.

Por essa ocasião, os únicos textos que circulavam nas comunidades eram bilhetes e cartas. Os bilhetes, enviados, em geral, através de crianças para moradores da cidade, e através da ambulância ou do transporte dos estudantes para moradores da zona rural, substituíam os telefones inexistentes. As cartas eram dirigidas a parentes que tinham ido buscar novas oportunidades de emprego em outros estados. O uso da escrita em órgãos públicos era restrito aos funcionários ou a pessoas trazidas de fora para o trabalho. Não havia jornais nem revistas.

Diante dessa situação, buscou-se propiciar a construção de uma rede de letramento envolvendo os habitantes escolarizados e os jovens e adultos em fase inicial de aprendizagem da escrita (TERZI, 2001a,b), pois de nada adiantaria o desenvolvimento do letramento crítico em sala de aula, se os alunos não encontrassem, fora da escola, condições de uso da escrita. A reprodução, em forma de cartazes, dos anúncios apresentados pelo carro de som, a introdução do jornal mural, com notícias de interesse local, na praça central e o início de montagem de uma biblioteca foram os primeiros passos de promoção de um contato maior da população com textos escritos. Conforme havia sido previsto, isso causou inicialmente uma reação negativa. De fato, como percebiam os alfabetizadores, não havia função para os cartazes, já que, devido ao grande número de analfabetos, o carro de som teria que continuar anunciando os eventos e as ocorrências importantes. Entretanto, o objetivo de ampliar a presença pública da escrita foi posteriormente entendido. Quanto ao jornal mural, a reação contrária veio da oligarquia governante, que não queria que fossem tornados públicos fatos envolvendo amigos e correligionários. Porém, os cartazes e o jornal atraíam a atenção dos que passavam pelo local e eram muitas vezes arrancados e levados para casa, por pessoas que não liam ou o faziam com dificuldade, para que fossem lidos por parentes ou amigos. Com 
o passar do tempo, novos tipos de cartazes foram espontaneamente surgindo na igreja, nas escolas e em casas comerciais, informando sobre eventos, preços promocionais, venda de objetos usados etc., fazendo com que o uso desse meio de comunicação passasse a fazer parte do cotidiano da comunidade. A presença do jornal mural, por sua vez, resultou no interesse por esse tipo de leitura e, conseqüentemente, na necessidade de acesso a outras notícias. Hoje, um dos municípios já conta com trinta assinaturas de um jornal produzido na capital. A sala de leitura, iniciada com livros doados, atraía principalmente as crianças, que ainda não tinham tido contato com obras infantis, e os jovens, em busca de orientação para os trabalhos escolares.

O papel dos professores foi importante na construção da rede de letramento. A seleção, em grupo, dos textos para serem discutidos em sala de aula exigia muita leitura, e os significados construídos eram socializados não apenas na comunidade escolar, mas também entre parentes, amigos, vizinhos. Foi dentro desse quadro que se buscou propiciar o desenvolvimento do letramento crítico dos sujeitos da pesquisa.

\section{O letramento em sala de aula}

A base teórica subjacente a este trabalho é constituída pelas pesquisas na área de Letramento Crítico (FEHRING e GREEN, 2001) e na área de Estudos Sócio-culturais do Letramento (The new literacy studies) (HEATH, 1983; STREET, 1984, 1995; BARTON e HAMILTON, 1998; GEE, 1990, 2000; KRESS, 1985).

Entretanto, o letramento não pode ser considerado como apenas o uso cultural da escrita, pois, mesmo sem saber ainda usá-la, como é o caso dos analfabetos, o indivíduo detém algum conhecimento sobre ela. Consideramos, então, o letramento como a relação que as pessoas estabelecem com a escrita (TERZI, 2003), seja ela uma relação de uso, de conhecimento, de valorização ou de crença sobre a escrita. A relação de conhecimento não envolve somente o conhecimento lingüístico; ela é muito mais ampla, abrangendo a compreensão das práticas sócioculturais que se realizam através de textos escritos, a função dessas práticas e, conseqüentemente, a função dos textos e as formas lingüísticas apropriadas para tais atividades sociais dentro do contexto cultural em que se concretizam. Esse conhecimento potencializa a 
valorização da apropriação das práticas de letramento, que, por sua vez, faz surgir a necessidade de maior conhecimento. Por ser um fenômeno social que exige a focalização dos padrões culturais próprios de grupos sociais específicos, o letramento crítico é influenciado por esses padrões e ao mesmo tempo os influencia, definindo-os e transformando-os.

Portanto, embora o curso considerado nesta pesquisa seja chamado de alfabetização, sua meta não é apenas alfabetizar os alunos, permitindolhes dominar a tecnologia da escrita para que, posteriormente, venham a conhecer as práticas sócio-culturais em que a escrita se insere. $\mathrm{O}$ objetivo é propiciar o desenvolvimento do letramento dos alunos, ou seja, a ampliação e o aprofundamento de sua relação com a escrita. Para tal, eles são levados a participar de práticas sociais de letramento, isto é, práticas que têm o texto escrito como elemento constitutivo, reproduzidas em sala de aula. Essa participação coloca-os em contato com variados usos da escrita em um curto espaço de tempo, o que, como já afirmado, difere do desenvolvimento natural do letramento.

Por ocasião do início do curso, os sujeitos tinham tido um contato muito pequeno com os usos da modalidade escrita da língua. Conheciam-na como meio de comunicação com parentes e amigos distantes. De cartas e bilhetes conheciam não apenas a função, mas também a forma, pois eram capazes de ditá-los a escribas, pessoas solidárias da localidade que os redigiam. Jornais e revistas, sabiam que existiam e que traziam notícias, mas nunca os haviam visto ou manuseado e, portanto, desconheciam a experiência de pelo menos ouvir um texto desse tipo lido. Os que tinham tido contato com pessoas que já haviam tentado uma nova vida em cidades grandes falavam da ficha exigida para concorrer a um emprego em empresas, mas sem entender sua função e forma. A escrita ambiental que, em 1997, se resumia a placas de identificação de alguns estabelecimentos comerciais e instituições públicas nas cidades, embora já se tivesse ampliado no período estudado, continuava por eles ignorada, uma vez que se mostrava inútil, num lugar em que tudo é conhecido.

Essa situação de letramento foi o primeiro fator orientador da seleção das práticas de letramento a serem reproduzidas em sala de aula. Um segundo fator foi a necessidade imediata de aprendizagem da escrita, apresentada pelos alunos. Ao contrário do que ocorre com as crianças que iniciam seus estudos escolares, jovens e adultos, ao procurarem cursos de alfabetização, já têm uma experiência de vida e a percepção das 
limitações impostas pela situação de analfabetismo. Conseqüentemente, identificam com clareza suas necessidades imediatas de uso da escrita, necessidades essas que, uma vez satisfeitas, viriam a amenizar suas dificuldades do cotidiano. Atender a essas necessidades garante a satisfação dos alunos, a valorização da escrita e sua permanência na escola. Entretanto, limitar a exposição dos letrandos a essas práticas utilitárias de letramento significa limitar sua capacidade de funcionamento social como cidadão letrado à comunidade a qual pertencem. O letramento de um dado grupo social é caracterizado no espaço e no tempo, influenciado pelas e influenciando as condições sócio-econômicas e culturais locais, embora seja historicamente construído. Ao passar a fazer parte de outros grupos sociais, situação comum entre os nordestinos que, fugindo das secas, buscam empregos em outras regiões, jovens e adultos encontrarão outros variados usos da língua escrita, para os quais deverão estar preparados.

A fim de tornar mais claro o trabalho desenvolvido em sala de aula, durante os cinco meses de curso, com os sujeitos da pesquisa, sintetizamos as principais práticas de letramento em que foram envolvidos e os tipos de textos escritos que as integram, não necessariamente nesta ordem:

Prática sócio-cultural de identificação do indivíduo como cidadão: Atestado de Nascido Vivo, Certidão de Nascimento, Cédula de Identidade, Cadastro de Pessoa Física, cadastros em geral

Prática sócio-cultural de comunicação através da escrita ambiental: placas de identificação de logradouros públicos, de estabelecimentos comerciais e instituições públicas, mensagens em muros e propagandas

Prática sócio-cultural de comunicação através da escrita em produtos comercializados: rótulos

Prática sócio-cultural de comunicação interpessoal: bilhetes, cartas

Prática sócio-cultural de busca de informações através da escrita: textos jornalísticos e de revistas

Prática sócio-cultural de busca de entretenimento e lazer através da escrita: contos, crônicas, poemas

Essas práticas foram realizadas de forma a permitir a compreensão de sua função num contexto sócio-cultural e de sua relação de poder. A partir delas, foram desenvolvidos os trabalhos de leitura e produção de textos e o ensino do código da escrita, focalizando-se sempre o texto 
como objeto social, além de lingüístico. A alfabetização, então, difere daquela dos processos tradicionais, por ser o domínio de uma tecnologia que permitirá o uso de palavras, frases e textos que têm sua função nas práticas sociais.

Para esse trabalho, foram selecionados alfabetizadores, dentre professores, estudantes de Ensino Médio e demais membros da comunidade. A seleção, efetuada através de testes escritos, entrevistas e análise de currículos, teve como critérios o domínio da língua escrita e, apesar das limitações do processo, a responsabilidade e o espírito solidário, uma vez que pelo trabalho receberiam apenas uma pequena ajuda de custo. Entretanto, em regiões de difícil acesso, o critério principal foi residir no local.

Os alfabetizadores selecionados receberam uma formação intensiva na Universidade, por um período de vinte dias, oferecida pela equipe que coordena o Programa, e uma formação continuada, realizada mensalmente nos municípios, quando das visitas de acompanhamento. Simultaneamente, receberam o apoio da coordenadora municipal e da orientadora pedagógica, professoras locais selecionadas para os cargos, em reuniões quinzenais.

Era nossa expectativa que esse trabalho gerasse transformações no conceito de escrita dos alunos. Daí o objetivo da pesquisa de identificar e analisar essas transformações.

\section{A pesquisa}

Participaram da pesquisa jovens e adultos não escolarizados, matriculados em vinte turmas do Programa. Os dados foram coletados através de entrevistas individuais, realizadas no início e no final de um curso de cinco meses. No início do curso, todos os alunos foram entrevistados. Entretanto, no final, foi possível entrevistar apenas 86 deles. Portanto, somente os dados dos que participaram de ambas as entrevistas foram considerados para a pesquisa.

Dado o grande número de alunos, as entrevistas iniciais foram feitas pelos próprios professores alfabetizadores, devidamente preparados para a tarefa. As perguntas orientadoras da entrevista individual eram: para que o aluno queria aprender a ler e a escrever e, segundo ele, em que essa aprendizagem mudaria seu cotidiano. As respostas dadas 
foram registradas por escrito. Já as entrevistas finais, foram feitas pelas pesquisadoras, gravadas em áudio e, posteriormente, transcritas. Nessas, os sujeitos foram estimulados a, principalmente, falar dos efeitos de sua aprendizagem da escrita, dos usos que já conseguiam fazer dela e que outros usos pretendiam fazer quando a dominassem melhor. Cabe lembrar, aqui, que cinco meses de aulas não são suficientes para um domínio do código da escrita que permita a leitura e produção de textos de maneira independente.

A coleta de dados através de perguntas orientadoras e não de perguntas fechadas deveu-se ao fato de pretendermos captar usos da escrita que não nos fossem previstos.

\section{Análise dos dados}

Os tópicos de análise foram definidos a partir das práticas de letramento transformadoras do conhecimento sobre si mesmos e sobre a realidade, e das práticas potencializadoras da participação e inclusão social, citadas e comentadas pelos entrevistados.

Os tópicos que apresentaram resultados significativos foram: a escrita como meio de obtenção e manutenção de emprego; a escrita como meio de evitar a discriminação; a escrita como meio de comunicação interpessoal; a escrita como meio de localização espacial; a escrita como fonte de informação; a escrita como meio de construção do pensamento crítico; a escrita como fonte de lazer; a escrita como meio de participação familiar; a escrita como meio de participação social; a escrita como meio de participação religiosa e a escrita como um instrumento de poder.

Embora a abordagem de análise seja qualitativa, consideramos importante, para uma melhor visão das transformações ocorridas, complementar essa análise com alguns dados quantitativos correspondentes à porcentagem de sujeitos que se manifestaram com relação a cada tópico durante as entrevistas.

Os dados da entrevista inicial e da final, relativos a cada tópico, serão apresentados simultaneamente, para fins de comparação. Iniciaremos com a apresentação dos tópicos que se mostraram mais relevantes aos sujeitos no início do curso. 


\section{A escrita como meio de obtenção e manutenção de emprego}

O alto índice de referência à escrita como meio de obtenção de trabalho - 39\% dos sujeitos a mencionaram nas entrevistas iniciais e 40\% nas finais - se justifica pela situação difícil que caracteriza toda a região, com a falta de empregos, salários baixos e a seca prejudicando a produção agrícola. Ir para os grandes centros não significa enriquecer, mas conseguir as condições mínimas de vida para si e para a família que lá ficou. Entretanto, os dados das entrevistas finais revelam uma significativa mudança. No início do curso, a escrita era vista como um meio de, fugindo da seca, encontrar trabalho em uma cidade grande. Sabiam, através de pessoas que já haviam tentado a experiência, que para isso deveriam ser capazes de ler os anúncios de vagas e preencher uma ficha, candidatando-se ao emprego. Não há, nessa fase, ocorrência de usos previstos para a escrita na solução dos problemas de emprego na própria comunidade. Entretanto, esses usos aparecem nas entrevistas finais.

A escrita como constitutiva da prática de seleção de funcionários surge agora com referência à promoção no emprego local, como evidencia a fala de uma cozinheira:

Melhorava se eu soubesse ler mesmo, não vivia que nem vivo, trabalhando num emprego ganhando $\mathrm{R} \$ 50,00$ por mês, ainda recebe em duas vezes, e se eu soubesse ler, podia estar ganhando mais, poderia no meu setor mesmo eu ser parteira.

A escrita surge, também, como meio de manutenção de emprego na própria cidade:

Perdi o emprego de doméstica porque não sabia receber correspondência (assinar) e escrever número de telefone.

Relacionada à mesma prática, aparece a escrita como fonte de informações necessárias para o bom desempenho no trabalho. Um sujeito afirma:

Quero ter leitura para arrumar emprego, que a pessoa quando arruma um emprego, a pessoa tem também livros que a pessoa precisa ler para conhecer como é que vai se trabalhar.

Além da busca e manutenção do emprego, algumas falas evidenciam a visão da escrita como um meio para o trabalho autônomo, principalmente com a função de registro: 
A gente tem que saber ler para não trabalhar para os outros senão a gente nunca tem uma vida melhor...porque para a gente negociar, se a gente não souber ler, aí vai trabalhar no comércio, a gente não sabe assinar o nome de uma pessoa, de um freguês, aí fica difícil.

Outro sujeito afirma:

Eu vendo umas coisinhas aqui, se eu anotasse, você vende fiado, aí tem que pedir aos outros...a gente sabendo ler, tudo isso a gente escreve.

Os dados mostram que a participação dos sujeitos nas práticas de letramento, propiciada pelo curso, permitiu uma ampliação do conceito de escrita. Se no início ela tinha função apenas na busca de emprego em grandes centros, no final ela passa a ser vista como parte relevante do processo de obtenção e manutenção de trabalho nos municípios e de progressão na carreira, além de integrar a prática de trabalho autônomo. Essa mudança evidencia um aprofundamento da relação dos alunos com a escrita, um conhecimento maior de suas funções sociais e, conseqüentemente, uma maior valorização da mesma.

Do ponto de vista do cidadão, os dados nos permitem inferir que, para esses sujeitos, a saída da região já não é mais a única solução para o problema de emprego, mas que as condições locais de trabalho também podem ser melhoradas através do domínio da escrita.

\section{A escrita como meio de evitar a discriminação}

A discriminação dos analfabetos, presente em qualquer sociedade, está subjacente a praticamente todos os depoimentos dos sujeitos. Por não dominarem a língua escrita, eles são considerados ignorantes, incapazes de refletir e de opinar. Excluídos da participação social, eles se sentem inferiores e se isolam. Esconder sua situação de analfabetismo é, então, uma estratégia por eles utilizada para evitar pelo menos parte da discriminação.

Por ocasião da implementação do Programa Alfabetização Solidária nos municípios, a situação de analfabetismo dos habitantes não tinha que necessariamente se tornar pública. Como o uso da escrita era raro, era comum os alunos não saberem se os pais eram alfabetizados, apenas afirmavam nunca tê-los visto lendo ou escrevendo. A questão nem era colocada na família. Entretanto, com a criação do programa de aposentadoria rural, a inabilidade de assinar o recibo no banco se 
tornava pública. A necessidade de "botar o dedo", como dizem, diante dos demais membros da comunidade, feria ainda mais a auto-estima dos adultos. Daí um grupo de sujeitos (25\%) ter, na entrevista inicial, focalizado a importância da escrita na assinatura de documentos, do recibo da aposentadoria e da renovação da matrícula dos filhos na escola. A justificativa incluía sempre a vergonha de não saber assinar, o fato de sentir-se mal por isso e de achar isso "muito feio". Os demais sujeitos não comentaram a questão, provavelmente porque, por já terem freqüentado a escola anteriormente, conseguiam desenhar o próprio nome, mesmo que de maneira inadequada.

No final do curso, um grupo menor de sujeitos (12\%) enfatizou a importância da habilidade de escrever o nome. Porém, como esses sujeitos já haviam adquirido essa habilidade, salientaram o prazer de assinar em público e de terem trocado os documentos que os identificavam como analfabetos. Eliminar essas condições que evidenciam o analfabetismo muitas vezes significa para eles uma mudança de status.

A mudança, portanto, com relação a esse item, dá-se em forma de maior uso da escrita, aqui da assinatura do nome na identificação do cidadão, pois a prática já era conhecida e valorizada, e tem forte impacto na auto-estima dos sujeitos.

\section{A escrita como meio de comunicação interpessoal}

A prática de comunicação com parentes e amigos através de bilhetes e cartas já fazia parte do cotidiano das comunidades. Como foi dito anteriormente, a existência de poucos telefones fez com que bilhetes se transformassem em um dos textos que mais circulam entre os habitantes. Na zona rural, pedidos de compras, comunicados de batizados, festas religiosas, doenças etc. são feitos através de bilhetes. Na cidade, eles são usados em geral para atender necessidades imediatas, ou seja, para resolver questões que não podem aguardar um encontro pessoal. Por outro lado, o grande número de familiares que trabalham em regiões distantes e o alto custo de telefonemas fazem com que a quantidade de cartas enviadas e recebidas seja grande.

Essa prática de comunicação é conhecida por todos em sua função e na forma dos textos que a integram. Entretanto, devido à condição de analfabetismo da maior parte da população, esses textos são, em geral, redigidos por vizinhos ou amigos que sabem ler e escrever. 
O fato de as cartas serem escritas por terceiros gera dois problemas: o da desconfiança sobre a fidelidade das informações colocadas e o da falta de privacidade. Uma forma de garantir a fidelidade é a exigência de leitura do texto após a escrita, muitas vezes seguida de pedidos de mudança na maneira de expressão.

Quanto à privacidade, ou seja, o fato de outras pessoas - os escribas - tomarem conhecimento do assunto das cartas e, portanto, poderem comentá-lo com outros membros da comunidade, a fala de um sujeito é representativa. Ele diz:

Se não sabe ler, aí vai precisar de mandar os outros, vai com medo de os outros, às vezes tem negócio importante que não pode dar nenhum saber para todo mundo, porque tem muitas coisas que a pessoa escreve para os outros e não quer nem que estabeleça a história, aí quer dizer que a gente tem muita vontade de aprender, né? Eu mesmo sinto.

Duas outras falas expressam os sentimentos com relação à habilidade de escrever e ler cartas. O sentimento quanto à inabilidade:

Ainda estou pedindo para os outros ler, escrever, é o maior desgosto que eu tenho, é esse, é vir a carta e os outros entender mais primeiro do que eu.

O sentimento quanto à habilidade conseguida:

Mandei uma carta, uma mensagem para minha mãezinha, foi a coisa mais importante da minha vida.

As motivações e os sentimentos apresentados pelos sujeitos quanto à comunicação via cartas são os mesmos no início e no final de curso. O grande aumento de manifestações a respeito do tópico nas entrevistas finais - de $16 \%$ para $77 \%$ dos sujeitos - é, provavelmente, uma conseqüência do fato de os alfabetizandos, após cinco meses de curso, já serem capazes de redigir cartas pequenas e simples, com a ajuda dos professores. Isso refletiria a percepção de estarem próximos da autonomia quanto a esse uso da escrita, e o estímulo gerado por essa percepção.

Os tópicos até aqui discutidos mostram os níveis inicial e final de letramento dos sujeitos, gerados pelas suas necessidades mais imediatas, e influenciados pelos padrões de significação locais e pelas relações de poder. Assim, para eles, saber escrever o próprio nome significa dar um passo a mais no processo de letramento, diferenciar-se daqueles que não sabem fazê-lo, participar socialmente, como os demais, ao assumir compromisso através da assinatura, e evitar a discriminação por 
não ter que evidenciar publicamente sua condição de analfabeto. Ler e escrever as próprias cartas significa autonomia e poder. Conhecer e dominar novos usos para a língua escrita no campo de trabalho significa a possibilidade de uma vida melhor. Portanto, o texto escrito não é, para os sujeitos, apenas um objeto lingüístico integrante das práticas escolares. Ele é um objeto sócio-lingüístico, que faz parte das interações sociais, culturais, comerciais e de poder entre os membros da comunidade.

\section{A escrita como meio de localização espacial}

A utilização de placas identificatórias de meios de transportes, de ruas, de estabelecimentos comerciais e industriais para a circulação numa cidade não faz parte da vida diária dos moradores dos municípios investigados. Por terem área e população limitadas, seus habitantes caminham até o trabalho, e conhecem a função de cada prédio existente e os moradores de cada casa. Esse tipo de escrita não tem, portanto, função local.

O motivo apresentado pelos sujeitos, nos dois momentos de entrevista, para a importância da escrita indicativa é a falta de autonomia do analfabeto para transitar em uma cidade grande, aliada à má vontade dos transeuntes em dar informações, conforme mostram as falas seguintes:

Se a gente for viajar para fora, quer dizer, quem sabe ler um pouquinho também, não vai depender dos outros, aí tudo fica mais fácil para a gente; sabe pegar um carro, um ônibus, sabe onde parou, onde está.

(Sabendo ler) a pessoa sabe nome de rua, número de casa, sabe para onde vai, a pessoa sabe ir, não anda perguntando para ninguém.

... fica perguntando, os outros tem má vontade, não ensinam direito.

A pessoa não sabendo ler só anda guiado. Não pode visitar os parentes porque tem medo de ir só.

Entretanto, as manifestações desse uso da escrita são muito mais numerosas nas entrevistas finais, quando 31\% dos sujeitos o mencionam, enquanto apenas $4 \%$ deles o fazem na entrevista inicial.

Buscar uma vida melhor em grandes centros urbanos, mesmo que por tempo limitado, faz parte do sonho da maioria dos nordestinos dessa região. Porém, a dificuldade de, como analfabetos, transitar nesses locais, tem sido um impedimento para muitos. Aparentemente, 
o trabalho desenvolvido em sala de aula com dados de orientação espacial permitiu aos alfabetizandos redimensionar esse impedimento, por sentirem-se já um pouco mais próximos do domínio do uso da escrita ambiental.

\section{A escrita como fonte de informação}

As práticas de letramento até então discutidas eram parcialmente conhecidas pelos alunos e, portanto, as mudanças se deram quanto ao aprofundamento desse conhecimento e início ou ampliação do uso. Já as práticas relacionadas aos próximos tópicos e seus efeitos no leitor/ produtor de texto eram praticamente desconhecidas dos sujeitos, sendo os dados, portanto, conseqüentes do conhecimento adquirido durante o curso. A valorização da escrita como fonte de informação é muito mais mencionada nas entrevistas finais $-67 \%$ dos sujeitos o fazem, contra $13 \%$ na entrevista inicial.

As manifestações iniciais podem ser resumidas no desejo de ter mais informações, porém sem expressar qualquer expectativa com relação aos efeitos dessa aquisição.

Embora os alunos tenham, durante o curso, participado de leituras de diferentes textos, o jornal se mostrou, sem dúvida, o meio mais poderoso de conhecimento da realidade. Os sujeitos sabiam da existência de jornais e que eles traziam notícias, porém, dadas as condições locais, não tinham tido acesso a eles, conforme exemplificam as afirmações:

Eu nem sabia o que era o jornal e hoje eu sei.

Eu nunca tinha visto a leitura do jornal, aí ela (a professora) leu, trabalhou com o jornal, aí nós vimos.

Nas entrevistas finais, os tipos de informação jornalística salientados pelos sujeitos variam muito. O rompimento do limite local de conhecimento imposto pela oralidade é valorizado:

(É importante saber) coisas que acontecem aqui, em outras cidades, no Brasil aí afora, em outros lugares que a pessoa nem sabe.

Esse interesse aparece, também, associado à existência de parentes residindo em locais distantes:

Às vezes tem família fora, aí você sabe (o que se passa lá). 
Interesses do cotidiano também são mencionados:

O jornal informa sobre o que acontece, sobre salários, até sobre as escolas. A gente mora aqui e não sabe de nada, aí pelo jornal fica sabendo. ...notícia de chuva, de plantação.

Uma pessoa informada é sempre bom, porque se você está por dentro das coisas que acontecem no dia-a-dia do país, já que o Brasil é um país que tem muitos políticos, sei que eles podem não fazer o melhor para o país, mas a gente tem que estar por dentro.

O acesso à informação não apenas fez com que os sujeitos se considerassem mais "sabedores", mas levou-os a avaliar e a expressar os efeitos dessa sabedoria no indivíduo. São várias as maneiras pelas quais os alfabetizandos interpretam as próprias mudanças, provavelmente refletindo percepções individuais de alterações na auto-imagem:

(A leitura) desenvolve a gente. A gente que é nascido e criado na roça é um pouco, assim, meio, não é bem desenvolvido, né? A gente é um pouco meio matuto.

O jornal faz pensar, deixa a pessoa informada, eu gosto, me sinto melhor.

A gente sabendo das coisas é uma pessoa melhor.

É bom ler para ser mais gente, para entender das coisas.

Lendo a gente está descobrindo as coisas, desenvolve mais. Quem não lê é devagar.

(Quero ler) para ser uma pessoa mais ativa, mais inteligente.

Essa perspectiva chega a envolver uma mudança de status-daquele que aprende àquele que ensina:

Lê... fica sabendo, fica na posição de um cabra que sabe ensinar.

Como vemos, todas as transformações mencionadas pelos sujeitos são apresentadas de forma muito positiva, o que, se por um lado evidencia uma relação benéfica entre os efeitos do contato cada vez mais intenso com o mundo letrado e a satisfação pessoal dos alunos, por outro lado mostra o perigo de se atribuir à escrita poderes que ela não tem.

Assim, observamos que há uma linha tênue entre o que o letrando considera como positividade da escrita e uma crença nessa escrita como redentora dos males que oprimem esses sujeitos em quase todos os domínios de suas vidas, sejam pessoais ou sociais. 
É essencial, porém, que interpretemos essas afirmações com base no significado que os termos utilizados têm na comunidade investigada. Desse modo, quando o sujeito define-se como "matuto", por exemplo, quer dizer que evita se expor, preferindo ficar calado por medo de "errar", ou seja, por medo de não saber se relacionar com as pessoas mais letradas de acordo com os valores e padrões comportamentais dessas pessoas, de modo que, sob o ponto de vista do letrado/ intelectualizado, ele de fato "não é bem desenvolvido" e só o será quando, tendo maior conhecimento da cultura escrita e acesso a ela, passará a participar de conversas com pessoas que pertençam a ambientes sócioculturais diferentes do seu, sentindo-se à vontade para opinar, argumentar, discutir. Nessa ocasião, ele acredita que se sentirá mais "gente", ou seja, mais aceito socialmente porque mais consciente de seus direitos e, portanto, mais respeitado, capaz de defender seus interesses e não se deixar controlar pelos outros, isto é, tornar-se-á um cidadão.

Acreditam também que a escrita fará deles pessoas "melhores", termo que para eles está associado não necessariamente à benevolência, mas à capacidade de enfrentamento das dificuldades e operacionalização dos problemas em busca de soluções. Para eles, quem sabe ler é uma pessoa "mais ativa, mais inteligente", porque não se deixa enganar, é perspicaz, compreende os fatos sem precisar que alguém os explique detalhadamente. Não é "devagar", ou seja, passivo, incapaz de se colocar na sociedade e lutar pelas coisas de que necessita.

É importante lembrar que a referência dos sujeitos é o professor, aquele que, para eles, por saber ler, apresenta essas características. Atingir o nível de conhecimento e de participação e reconhecimento social do professor é o que almejam.

Além dessas informações comentadas, a escrita é citada também como fonte de dados para o aperfeiçoamento da língua oral. Como sabemos, em comunidades predominantemente orais é muito freqüente a pronúncia de palavras diferente da pronúncia padrão. $\mathrm{O}$ acesso à língua escrita permitiu a percepção dessas diferenças:

(A gente) não sabe dizer uma palavra certa, aí a gente vai ler, em vez de a gente usar a palavra errada, a gente diz o que está escrito. Eu acho que do jeito que está lá está certo porque está escrito.

Embora a língua padrão seja tratada nos cursos como uma maneira diferente, mas não superior, de expressão, aprender a falar também como as pessoas escolarizadas é muito valorizado pelos alfabetizandos. 
Vemos, assim, que a escrita é portadora de muitas promessas para os alunos e, embora saibamos que muitas delas podem se cumprir e têm se cumprido, não ignoramos que muitas delas têm um caráter mitificado, como discutiremos mais à frente. Sabemos, por exemplo, que, em algumas circunstâncias, a escrita pode ser fundamental para que alguém resolva um problema, mas não podemos afirmar que alguém conseguirá resolver a maioria de seus problemas com facilidade, apenas porque sabe escrever. Da mesma forma, embora o desenvolvimento do letramento seja condição sine qua non para que haja participação social ou cidadania, essas não podem ser vistas senão como entidades complexas que dependem de fatores de diversas naturezas, não apenas do letramento.

Ainda assim, a discussão apresentada mostra que a participação dos sujeitos em práticas até então desconhecidas ou pouco conhecidas de letramento, práticas que ainda não eram próprias de suas comunidades, causou uma significativa ampliação da relação que estabeleciam com a escrita.

\section{A escrita como meio de construção do pensamento crítico}

Pelas próprias condições locais, analisar criticamente a realidade circundante, posicionar-se quanto aos fatos, propor soluções para os problemas não é rotina entre a população menos favorecida da região investigada. A maioria reside na zona rural, em sítios distantes uns dos outros, sem acesso a jornais ou revistas, e muitos sem acesso também à televisão, por não disporem de energia elétrica. A feira livre semanal e algumas festas religiosas são, para eles, em geral, os únicos pontos de encontro com outros membros da comunidade. A falta de acesso à informação e o isolamento em que vivem são, por si só, fatores cerceadores de questionamentos e troca de opiniões. Além disso, a igreja local, pregando a existência de um Deus que decide sobre a vida das pessoas, provavelmente estimula a aceitação dos fatos sem julgamento. Por sua vez, o regime oligárquico, que determina as normas a serem seguidas, entre elas a de não criticar os governantes, e que pune os infratores com o não acesso a empregos e serviços públicos, desestimula qualquer forma de expressão de opiniões.

Aparentemente, as discussões e os questionamentos conduzidos pelos professores sobre vários temas em sala de aula durante o curso 
estimularam a reflexão dos alfabetizandos. A escrita, então, além de fonte de informações, passaria a ser vista, também, como um meio de estabelecer comparações e reavaliar posições. Talvez isso explique o fato de, na entrevista inicial, nenhum dos sujeitos ter mencionado a escrita como fonte de desenvolvimento de alguma forma de pensamento mais crítico, enquanto $28 \%$ deles o fizeram na entrevista final. A fala de um sujeito é significativa nesse sentido:

O jornal tem alguma coisa que a gente vai refletir e vai entender mais ... É, porque a pessoa tem que pensar, se a pessoa vai seguir isso, ou não vai, ela vai pensar. Se você está com aquele plano de fazer uma coisa, aí vai ver no jornal, aí não dá, ou dá, pode fazer isso. Aí você vai pensar 'Será que eu fazendo aquilo ali está certo ou está errado?' Aí a pessoa tem que pensar.

O exemplo revela o apoio nas informações do jornal, que agora passam a conhecer ou entender melhor, e na reflexão por elas geradas para o julgamento e a decisão sobre as próprias ações. É claro que o contato dos sujeitos com a escrita por tempo tão exíguo não lhes possibilitou, ainda, perceber que o fato de estarem escritas não garante a veracidade das informações. A percepção dessa possibilidade de apoio faz com que passem a desejar outras informações que lhes permitiriam melhor entender sua própria condição, a fim de sobre ela agir, como mostra a fala de outro sujeito:

(Queria saber) uma notícia mais melhor, um sistema de outro modelo que a gente não tem no lugar da gente, a pessoa deseja saber para aprender também. Modelo que eu digo assim de sistema de trabalho, de lei, de direito que a gente só sabe se ler e escrever. É importante saber dos direitos porque a pessoa fica uma pessoa consciente e não penetra no erro.

A escrita seria, então, um meio para conhecer outros modos de vida e, através da comparação e análise, melhor entender o modelo local.

A possibilidade de usar o conhecimento adquirido através da leitura para analisar criticamente, mesmo que de uma forma ainda superficial, a realidade em que vivem parece levá-los à busca da autonomia, ou seja, a não mais se orientarem pela opinião alheia, mas a agirem a partir de seus próprios posicionamentos. Algumas falas exemplificam esse fato: 
Se a pessoa sempre for fazendo as coisas pelos outros, a pessoa pode fazer uma hora certo, mas também pode fazer uma hora errado...E a pessoa quando tem certos entendimentos vai só continuar para frente, para trás nada. A pessoa quando sabe das notícias, aí quer dizer que não foi ninguém que disse à gente, foi a gente que viu pessoalmente porque leu e entendeu.

Porque os outros contam e para a gente é mentira, mas no jornal está vendo, está sabendo do que está acontecendo, porque o outro contando a gente fica meio na dúvida.

Saber pela boca dos outros pode até ser mentira, aí a pessoa vendo fica mais melhor, né?

As citações acima denunciam a desconfiança que têm no julgamento alheio e a valorização de formar suas opiniões a partir da interpretação da própria leitura. Como vimos em outros exemplos, há ainda nesse período a crença na veracidade total das informações impressas, embora uma certa criticidade com relação aos tópicos jornalísticos já comece a aparecer:

O jornal explica partes boas e partes ruins, aí a gente fica só com o bom, o ruim a gente deixa de lado. O importante é a gente ler no jornal, escolher as partes que são importantes para a gente.

O exemplo evidencia a percepção da importância da seletividade, e do direito a ela, o que é uma característica do leitor proficiente.

As mudanças acima apresentadas são relevantes porque refletem o desenvolvimento do cidadão autônomo, que busca assumir a condução de sua vida e que, para isso, se apóia na escrita.

\section{A escrita como fonte de lazer}

Embora os sujeitos ainda não estejam alfabetizados e, portanto, ainda não sejam capazes de independentemente ler e produzir os vários tipos de texto com que foram familiarizados, 14\% deles, ao final do curso, associam a escrita a alguma forma de lazer. O fato de o lazer somente ter sido mencionado nas entrevistas finais provavelmente se justifica pelo baixo nível inicial de contato dos participantes com práticas de letramento. Durante o curso, eles tiveram oportunidade de sentir os efeitos da participação na leitura de textos de tipos variados e, agora, esse efeito positivo se concretiza no desejo de um dia lê-los ou escrevê-los, pelo simples prazer que o ato lhes propiciaria. 
Os desejos de leitura são variados:

Eu gosto de ler sempre quando eu não estou fazendo nada, quando não estou trabalhando, é jornal, eu gosto de ler.

Leio na escola e quando a gente vai para a feira a gente pega (o jornal) e leva para casa e fica lendo.

Ler poema é muito divertido.

Quero ler o poema, né? Tenho muito prazer.

Também são variados os desejos de escrita:

Eu tenho vontade de escrever principalmente carta, poemas. Poemas é uma profissão que eu acho muito bonita.

(Quero) escrever verso, história.

Eu queria aprender escrever um diário.

Queria escrever assim histórias, é bacana.

Às vezes o desejo de ler está associado à profissão:

A revista agropecuária, como é? Globo Rural, tem muitas coisas da roça, do campo, eu gosto de ver isso que eu sou trabalhador do campo, então eu gosto dessas coisas.

Como vemos, a familiaridade desses sujeitos com os diversos gêneros já lhes permitiu compará-los e apontar suas preferências. Esse é um fato importante para a compreensão do processo de letramento: o conhecimento e o uso, mesmo que mediado, despertam o interesse e geram a necessidade de repetir a experiência. Forma-se, então, o leitor, a quem bastará a alfabetização para tornar-se um leitor/produtor de texto totalmente independente. Por outro lado, a pressa em atingir essa independência para atender seus interesses resulta em grande motivação do aluno para o domínio do código da escrita.

As citadas manifestações sobre a escrita como fonte de conhecimento, criticidade e lazer estão circunscritas à realização pessoal. Entretanto, os dados mostram, também, um aumento na relevância dada à escrita como meio propiciador de maior participação do indivíduo nas diversas esferas sociais. 


\section{A escrita como meio de participação familiar}

Três pontos são relevantes na visão da escrita como um meio de ampliação das relações familiares. O primeiro ponto diz respeito ao registro da própria história da família. Dado o grande número de filhos que caracteriza a maioria das famílias das comunidades investigadas, é comum os pais não se lembrarem exatamente do nome das crianças, mas apenas de seus apelidos. Por ocasião das matrículas no Programa, ocorre muitas vezes de os alunos descobrirem, pela Certidão de Nascimento, que têm um nome diferente daquele que sempre imaginaram ter. Portanto, conseguir escrever o nome dos membros da família significa registrar parte de sua história e buscar a cidadania. É isso que nos mostra, por exemplo, a fala:

Quero saber fazer os nomes. Eu não sei fazer o nome dos meus filhos, só sei fazer o meu, eu não sei fazer o nome do meu marido.

A necessidade de reconstruir a história familiar está expressa, também, no desejo de saber a idade dos filhos:

Eu quero estudar mais pra mor de saber da idade de meus filhos direito.

Um outro ponto relativo à participação na família diz respeito à possibilidade de auxiliar no letramento dos filhos, com as lições de casa:

A minha menina nova pegou os livros agora na escola, aí eu olho eles, que é desses grossões, e muita coisa eu não sei. Aí que se eu soubesse, eu já lia para ela, né, ela já ia decorando em casa.

ou com o preparo para a entrada na escola:

Queria pegar um livro, ler, que eu tenho uma filha, ensinar para ela, para quando ela entrar na escola, ela já saber de tudo.

Agora que eu sei o que é o jornal igual a minha filha vai saber o que é o jornal.

Há, ainda, a preocupação em educar os filhos:

Quero oferecer boas coisas, educação, para eles ficarem bem educados. Para educar precisa saber ler. Pega um pedacinho da Bíblia que diz assim e assim, e eles vão entendendo. E nem que eles não sabem ler, é melhor se a gente sabe ler, porque a gente orienta melhor.

A outra questão diz respeito à participação ativa nas conversas familiares. É comum, durante as aulas, os alunos reclamarem que ficam 
fora das conversas por falta de conhecimento sobre os assuntos. Os dados mostram que as leituras realizadas em sala de aula proporcionaram algum conhecimento que já lhes permitem uma participação maior, conforme afirma um sujeito:

Gosto do jornal porque a gente vai ficar lembrando daquilo depois, nem que não lembre de tudo, mas um filho vem perguntar 'Você sabe disso?' e eu digo 'Sei, é assim, assim, assim'.

Sentir-se em condições de igualdade com os filhos, tem, sem dúvida, um impacto positivo na auto-imagem do adulto.

Nas entrevistas iniciais, apenas 4\% dos sujeitos declararam o desejo de poder ajudar os filhos nas tarefas escolares ou de não serem mais ignorados durante as conversas. A ampliação do número de menções nas entrevistas finais - 10\% - provavelmente se deve ao fato de alguns já terem experimentado uma participação maior devido às leituras, e de outros já terem percebido a probabilidade de, em um curto período de tempo, estarem em condições de auxiliar seus filhos nos estudos.

\section{A escrita como meio de participação social}

Enquanto a participação social das pessoas não escolarizadas é cerceada pela discriminação, esta, por sua vez, faz com que elas se sintam inferiores e, conseqüentemente, evitem uma participação maior, numa espécie de círculo vicioso. Apenas $2 \%$ dos sujeitos mencionaram esse tipo de participação na entrevista inicial, todos no sentido de, aprendendo a ler e a escrever, poder auxiliar outras pessoas. Ao final do curso, 13\% dos sujeitos haviam percebido a potencialidade da escrita como um meio para a ampliação da participação na comunidade. Para eles, a escrita pode proporcionar a identificação com as pessoas mais escolarizadas e, conseqüentemente, a obtenção do respeito delas. A identificação se daria pelo desenvolvimento das mesmas habilidades de leitura e escrita:

A gente vê, assim, na feira, os cabras lendo tudo quanto é coisa. Eu quero saber ler aquilo também.

O fato de passar a fazer parte do grupo que lê e escreve significa, para esses sujeitos, passar a ser valorizado na comunidade:

(Quero aprender) para ter valor, né, ter prestígio. A pessoa que não sabe ler não tem voz ativa de saber conversar, aprender, de ter mais 
conhecimento, porque a pessoa que não sabe ler eu acho que não tem muito valor.

Assim, o domínio da escrita lhes traria o conhecimento necessário para participarem do grupo dos escolarizados, para serem por eles valorizados e respeitados. Porém, também esperam que a escrita os ensine a respeitar a cultura letrada, que, segundo sua visão, talvez eles nem saibam valorizar da forma que julgam ser apropriada, já que não têm intimidade com ela:

(Quero saber) para nós respeitarmos, porque, né, a gente quanto mais na letra, mais educado, né?.

Sabemos, porém, que essa idéia é decorrente de um discurso que circula socialmente, marginalizando o sujeito pouco letrado, considerado alguém carente da "luz" do conhecimento escolar, imagem que o próprio alfabetizando internaliza e reproduz.

É salientado, também, nos dados, o domínio da escrita como meio de ajudar outras pessoas:

(Quero) escrever cartas para os outros.

(Quero) ensinar um analfabeto, ensinar a assinar o nome.

(Quero) ajudar a pessoa que quer viajar.

Ou ainda:

Quando o cabra perguntar para a gente, a gente já pode explicar para ele as coisas que a gente soube.

Se isso por um lado reflete o espírito solidário característico das comunidades analisadas, por outro sugere a satisfação pela passagem da condição de aprendiz à condição de professor.

Essa compreensão da escrita como um elemento propiciador da inclusão social pode ser considerada como resultante do letramento crítico estimulado em sala de aula. Porém, na participação em grupos específicos, como é o caso da igreja, a escrita adquire funções diferentes.

\section{A escrita como meio de participação religiosa}

No período abrangido por esta pesquisa, segundo semestre de 2001, chegaram aos municípios as igrejas evangélicas, que passaram 
a ser freqüentadas por grande parte da população, inclusive dos sujeitos. Enquanto as igrejas católicas, de onde vieram os novos evangélicos, tinham como textos escritos apenas os folhetos de acompanhamento das missas e o catecismo, as recém - chegadas igrejas traziam a leitura da Bíblia Sagrada e de vários textos religiosos quase que como uma exigência. Daí o número significativo de sujeitos que passaram a ver, no domínio da escrita, um meio de participação ativa nos eventos religiosos. Apenas $2 \%$ das manifestações se referem a textos católicos.

Os textos mais citados pelos sujeitos em suas expectativas de participação nas igrejas foram a Bíblia, que aparece em quase todas as falas, e cânticos, novenas, livros de reza e catecismo. Como ainda não tinham habilidade para ler esses textos, o que aparece nas entrevistas é o desejo de poder lê-los, evitando a exclusão, como expressa um sujeito:

O meu desejo é eu ler qualquer passagem do evangelho, porque é o testemunho, é a reunião dos amigos; eles me chamam para a reunião, eu dou o testemunho, eu ajudo, mas eu estou fora da leitura.

Textos religiosos não foram trabalhados em sala de aula. Entretanto, a função deles na prática religiosa era conhecida dos alunos. Portanto, a significativa diferença entre o número de menções iniciais e finais com relação a esse uso da escrita deve-se mais à introdução, pelas igrejas, de novos textos na comunidade, gerando novas necessidades de letramento.

\section{A escrita como instrumento de poder}

Como afirmamos anteriormente, às vezes a pouca intimidade com o mundo da escrita, cuja realidade vai se revelando aos poucos ao aluno, pode levá-lo a uma relação um tanto fantasiosa com ela. Dessa forma, a partir da experiência de participação em práticas de letramento em sala de aula, um grupo de alunos passou a atribuir à escrita um poder que não condiz com a realidade. Esse poder, mencionado por $9 \%$ dos sujeitos na entrevista inicial e por 30\% deles na entrevista final, é apresentado por eles de maneira bastante vaga. Como ele não é conseqüente de experiências de vida, mas imaginado a partir delas, os alunos não têm condições de descrevê-lo claramente. O uso constante da palavra "tudo" revela a amplitude e a indeterminação desse poder. Fica claro, entretanto, que a escrita é vista como capaz de transformar as pessoas e a vida delas. Quanto à transformação da pessoa, duas falas são representativas: 
(Quero aprender a ler) para ver se um dia nós revivemos, ser o que eu nunca fui, né?

Porque (com a leitura) a pessoa enfrenta tudo.

Reviver, ser o que nunca foi, enfrentar tudo são, obviamente, realizações que estão além dos poderes da escrita. O mesmo acontece com relação à escrita como transformadora da vida dos indivíduos. Um sujeito sintetiza:

A leitura é tudo na vida da gente.

Outros afirmam:

É importante para tudo na vida.

Melhora muita coisa, tudo para a vida da gente.

A gente sabendo ler tem sempre coisas boas pra gente, na nossa vida. Tudo fica mais fácil pra gente.

Essa amplitude de poder atribuída à escrita tem sido chamada por alguns teóricos de "mitos do letramento", segundo os quais a escrita é concebida como um divisor de águas que distingue tipos de pessoas, sendo que as mais inteligentes, modernas, capazes e desenvolvidas em diversos aspectos são as consideradas letradas; ou distingue ainda os países mais bem comportados, civilizados e desenvolvidos (GEE, 1990). Assim, há "uma espécie de fé nos poderes, ou 'capacidades', do letramento como tecnologia fundamentalmente neutra - conhecimento das letras - e disponível, tanto ao desejo individual de sucesso na esfera pública quanto ao desejo coletivo de progresso e desenvolvimento" (SIGNORINI, 1994, p. 21). Há, então, uma supervalorização da escrita, vista não mais apenas como um instrumento para que o indivíduo possa lutar por sua inclusão social, mas como o único caminho capaz de levá-lo à redenção social e individual.

\section{Considerações finais}

Duas questões merecem ser aqui consideradas.

A análise dos dados nos mostra que a exposição dos alunos a práticas variadas de letramento em um curto espaço de tempo traz resultados bastante positivos. Houve uma ampliação e um aprofundamento na relação estabelecida pelos sujeitos com a escrita. Como foi dito no início 
deste trabalho, essa avaliação era importante, por se tratar de um processo de letramento crítico, diferente do natural. Neste, novas práticas de letramento são introduzidas paulatinamente na comunidade ao longo do tempo, a partir de um fato real desencadeador, enquanto, nos cursos, elas são planejadas com fins pedagógicos e apresentadas em apenas cinco meses. Esses resultados são especialmente importantes, por se referirem a jovens e adultos não escolarizados que, quando decidem procurar a escola, têm urgência em se tornarem capazes de utilizar a escrita em seu cotidiano.

Outra questão importante diz respeito à relação entre letramento e cidadania. Como foi dito, os tópicos de análise não foram definidos a partir das práticas de letramento reproduzidas em sala de aula, mas a partir da relevância a elas atribuída pelos alunos. Com base nesses tópicos, podemos perceber três tipos de relevância. Um deles é a valorização utilitária da escrita, ou seja, a escrita como um meio para resolver os problemas de trabalho, de comunicação com parentes distantes e de sobrevivência em grandes centros. As práticas de letramento relacionadas a esses problemas já eram conhecidas dos sujeitos e os avanços se deram mais na habilidade de leitura e produção dos textos que as integram. Entretanto, a partir da exposição a práticas desconhecidas, ou pouco conhecidas, surge um outro tipo de relevância - a escrita passa a ser vista, também, como meio de evitar a discriminação e como meio de crescimento e satisfação pessoal, através da aquisição de conhecimentos, da construção do pensamento crítico e da leitura/produção de textos como lazer. Esse tipo de relevância revela o cidadão em busca de si mesmo, de autoconhecimento e auto-valorização. Já o outro tipo de relevância, a escrita como meio de maior participação na família, na comunidade e na igreja, mostra o cidadão em busca de aceitação social e respeito. Considerando-se essas diferentes relevâncias, podemos, então, afirmar que o desenvolvimento do letramento é fortemente influenciado pela construção da cidadania, ao mesmo tempo em que a influencia. 


\section{Referências}

BARTON, D; HAMILTON, M. Local literacies: Reading and writing in one community. London: Routledge, 1998. 299p.

FEHRING, H.; GREEN, P. Critical literacy. Newark: International Reading Association, 2001. 174p.

GEE, J. P. Social linguistics and literacies: Ideology in Discourses. London: Taylor \& Francis, 1990.

GEE, J.P. Discourse and sociocultural studies in reading. In: KAMIL, L.K.; MOSENTHAL, P.B.; PEARSON, P.D.; BARR, R. (Ed.). Handbook of reading research. London: Lawrence Erbaum, 2000. 1010p.

HEATH, S. B. Ways with words: Language, life and work in communities and classrooms. Cambridge: Cambridge University Press, 1983.

KRESS, G. Linguistic processes in sociocultural practice. Oxford: Oxford University Press. 1985.

SIGNORINI, I. "A letra dá vida, mas também pode matá. Os "sem leitura" diante da escrita." In: Leitura: Teoria e Prática. Mercado Aberto: Campinas, n. 24, p.20-27, 1994.

STREET, B. Literacy in theory and practice. Cambridge: Cambridge University Press. 1984.

STREET, B. Social literacies: Critical approaches to literacy development, ethnography, and education. London: Longman. 1995.

TERZI, S.B. A experiência de letramento em Inhapi e Olho D'Água do Casado, AL. Revista do Programa Alfabetização Solidária, São Paulo, v.1, n.1, p. 143-155, 2001a.

TERZI, S. B. Para que ensinar a ler o jornal se não há jornal na comunidade?: o letramento simultâneo de jovens e adultos escolarizados e nãoescolarizados. In: RIBEIRO, V. M. (Org.). Educação de jovens e adultos: novos leitores, novas leituras. Campinas: Mercado de Letras. 2001b.

TERZI, S. B. Afinal, para quê ensinar a língua escrita. Revista da FACED, Salvador, n.7, p. 227-241, 2003. 